\section{Pacific Northwest}

National Laboratory

Operated by Battelle for the

U.S. Department of Energy

\section{A Case for Employing Near-field \\ Measurements to Detect Important Effluents from Nuclear Material Processing Operations}

\author{
J. S. Hartman \\ J. F. Kelly \\ J. C. Birnbaum
}

January 2007

Prepared for the U.S. Department of Energy under Contract DE-AC05-76RL01830 


\title{
A Case for Employing Near-field Measurements to Detect Important Effluents from Nuclear Material Processing Operations
}

\author{
J. S. Hartman \\ J. F. Kelly \\ J. C. Birnbaum
}

January 2007

Prepared for

the U.S. Department of Energy

under Contract DE-AC05-76RL01830

Pacific Northwest National Laboratory

Richland, Washington 99352 



\section{Summary}

The proliferation of nuclear weapons is a major international security threat. It is important to be able to detect nuclear processing operations that could enable either proliferant nations or subnational groups to obtain materials needed to develop and deploy nuclear weapons. In the ideal world, detection technologies would be available that could reliably detect, locate, and quantify all targeted reprocessing operations from large standoff distances. But this "magic tri-corder" technology does not exist. Monitoring may be performed by a combination of remote (i.e., large standoff distances), intermediate range, and near-field measurements. In situations where cooperative monitoring is practical, the intermediate and near-field measurements may be fairly easy to implement. In non-cooperative situations, the intermediate and near-field measurements are necessarily more challenging.

Chemical effluents released to the environment from nuclear processing plants can provide evidence of on-going processing operations. For some persistent effluents, environmental residuals can provide evidence of former operations. While the effluents may be monitored for occupational safety or environmental compliance, they may also be exploited to gain insights into the operations that produced effluents.

Critical processes targeted in this report include chemical reprocessing operations that extract plutonium $(\mathrm{Pu})$ and other Special Nuclear Materials (SNM) from irradiated nuclear fuel. Further, the report focuses on the opportunity to exploit important, persistent process chemical effluent signatures that can be found near nuclear material processing plants and their supporting facilities to support more effective nuclear non-proliferation monitoring.

The U.S. PUREX (Plutonium and Uranium Recovery by EXtraction) process and operations serve as the basis for this discussion as the PUREX process was disclosed during the Atoms for Peace era, and it has been adopted by many nations in the subsequent years. This report describes:

- Key chemical groups employed in the PUREX and nuclear materials reprocessing operations that offer significant process insights and exhibit persistence in the environment after release from the facility;

- Effluent release sources from the Hanford PUREX operation and its associated support facilities;

- Plume propagation after the effluent plumes are released from process stacks and the probability that under some common atmospheric conditions, the plume likely reaches the ground within several kilometers of the stack;

- The importance of considering the fate of chemicals in the environment to ensure that detection methods target viable signatures and in likely locations in the environment; and

- Results of a preliminary analysis of soil samples collected near the Hanford PUREX plant and its associated supporting facilities that confirmed the presence of persistent chemical residues indicative of the PUREX plant processes. 
In summary, the near-field domain around potential nuclear material reprocessing operations offers a valuable opportunity to detect chemical signatures that can be very important for understanding facility operations, including probable processes being employed. 


\section{Contents}

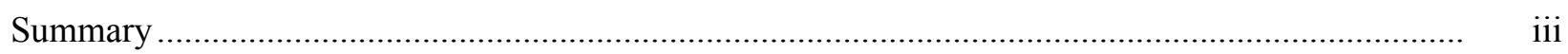

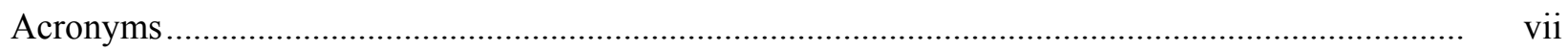

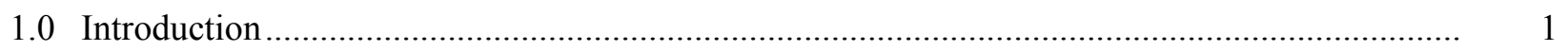

2.0 Motivation for Near-field Measurements for Detection of Nuclear Material Processing ............. 3

2.1 Chemicals Used in Nuclear Fuel Processing ................................................................. 5

2.2 Effluent Sources from Hanford-like Nuclear Reprocessing Operations............................. 8

2.2.1 Direct Releases during Plant Operations.......................................................... 8

2.2.2 Releases from Underground Waste Storage Tanks .............................................. 8

2.2.3 Releases from Cribs and Unintentional Outdoor Spills ....................................... 10

2.2.4 Summary Releases from Various Sources ......................................................... 10

2.3 Immediate Release Transport - General Observations on Atmospheric

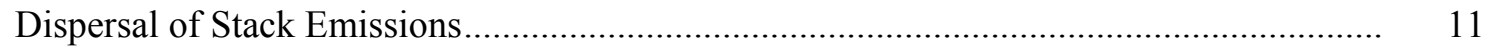

2.4 Process Signature Fate and Transport after Release to the Environment .......................... 15

2.5 Validation of Long-term Semi-volatile Residuals at Hanford ............................................ 17

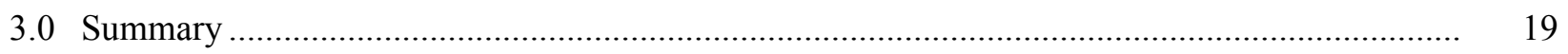

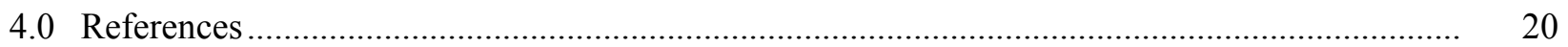




\section{Figures}

$1 \quad$ Signature Sensing and Monitoring Options are Illustrated for a Processing

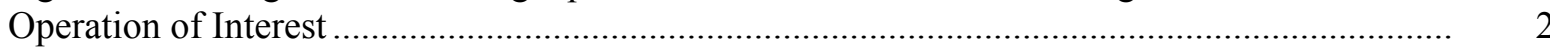

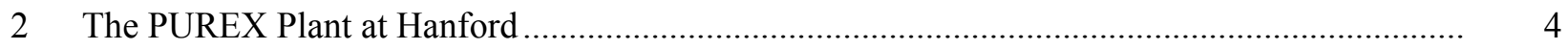

3 Summary of Results of Nuclear Processing Effluent Ranking based on Effluent

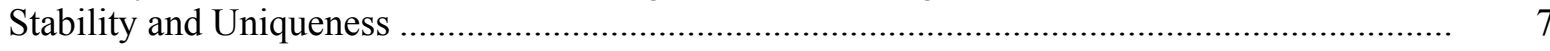

4 Hanford Nuclear Material Processing Operations Produced Effluents Directly from the Plant Stack, from Nearby Waste Storage Tanks, from In-ground Cribs, and from

open Trenches that Allowed Liquids to Seep into the Soil and Groundwater.

$5 \quad$ Illustration of Hanford Waste Tank Configuration Including Stratified Tank Contents and Important Contents and Interactions Typical for the Hanford PUREX Tanks

6 The Hanford T-plant is seen during Construction.

7 Normalized Predicted Air Concentration at Ground Level for Heavy, Semi-Volatile Effluents Released During Atmospheric Conditions Suitable for Effective Effluent Dispersion from Plume Trajectory Modeling.....

8 Map of the Hanford Site Identifying the 200 East Area Which Includes the Hanford PUREX Plant and a Number of Underground Waste Storage Tanks Used to Store Radioactive Waste Resulting from Past Hanford Nuclear Reprocessing Operations

\section{Tables}

1 Summary of Stability Analysis for 221 Chemicals used in Nuclear Fuel Reprocessing based on Volatility and Environmental Stability 


\section{Acronyms}

$\begin{array}{ll}\text { AP } & \text { activation products } \\ \text { CW } & \text { chemical weapon } \\ \text { DBP } & \begin{array}{l}\text { Di-n-butyl phosphate } \\ \text { dissolved off-gases }\end{array} \\ \text { DOGs } & \text { Fate and Transport } \\ \text { FP } & \text { fission products } \\ \text { MTU } & \text { metric tons of uranium } \\ \text { NPHs } & \begin{array}{l}\text { normal paraffinic hydrocarbons } \\ \text { NWSI }\end{array} \\ \text { National Weather Service Instruction } \\ \text { OP } & \text { organo phosphorus } \\ \text { Pu } & \text { plutonium } \\ \text { PUREX } & \text { Plutonium and Uranium Recovery by Extraction } \\ \text { SNM } & \text { Special Nuclear Materials } \\ \text { TBP } & \text { tributyl phosphate } \\ \text { TIC } & \text { toxic industrial chemicals }\end{array}$




\subsection{Introduction}

Chemical effluents released to the environment can provide evidence of industrial chemical operations. While effluents may be monitored for occupational safety or environmental compliance, they may also be exploited to gain insights into the operations that produce the effluents.

A variety of sensitive detection capabilities have been developed and deployed to monitor the presence and concentration of chemicals that are:

- Dangerous to workers and the general public (e.g., toxic industrial chemicals [TICs], chlorine, hydrogen sulfide, etc.);

- Important for understanding potential environmental effects (e.g., freons, green house gases, etc.); and

- Important for detecting and monitoring domestic and national security risks and threats (e.g., chemical weapon agents, chemical releases from illicit processes that may include weapons proliferation or drug production, etc.).

A specific monitoring technology may only address requirements for characterization of effluents from a specific process while other methods may be more universal. Multi-sensor and multi-platform approaches are currently being developed that will improve chemical detection and in many cases discriminate between typical and atypical process operations.

Chemical processes important for nuclear weapons development and production are the target of this examination. These operations can range from materials extraction from raw materials, nuclear fuel production, byproduct isotope separations for peaceful applications (including long-term waste storage) or weapons applications, etc. The processes can be operated openly by recognized governments for legitimate reasons or they may be operated covertly by governments or non-governmental terrorist organizations for reasons that threaten our national or international security arrangements. It is important to be able to detect and understand any illicit nuclear material processing operations that may pose significant threats. In many cases, suitable detection capabilities may not be currently available.

A broad variety of sensing and monitoring technologies have been employed and are being further developed. These range from sensors for deployment within facilities (under cooperative monitoring agreements) to remote observations by satellites. The range of options available is illustrated in Figure 1.

Several remote and/or near-field (i.e., at distances up to several kilometers from the source) measurement technologies can be used to monitor process activities in order to determine if processes of interest are in operation. Practical detection and sensing applications could use key physical and/or chemical observables that can be exploited to monitor these process activities. Valuable observables may include: (a) radioactive nuclear species, (b) chemicals, or (c) physical observables (i.e., changes in vegetation, unusual thermal effluents, etc.). Some observables may be definitive in that their detection could provide irrefutable evidence of the process being monitored. However, these definitive 


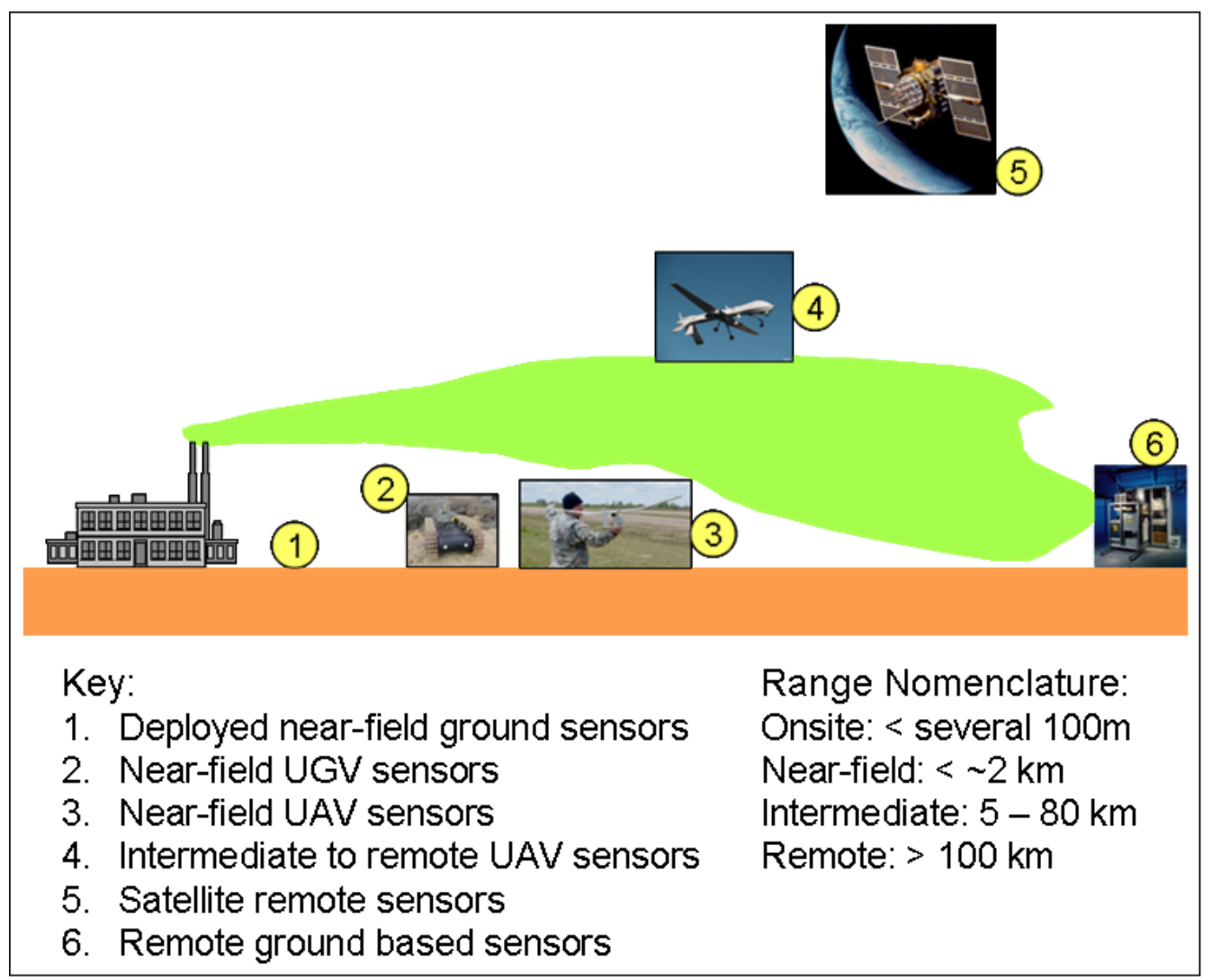

Figure 1. Signature Sensing and Monitoring Options are Illustrated for a Processing Operation of Interest

observables are often extremely difficult to capture because of episodic timing or measures taken to minimize detection (e.g., effluent scrubbers, etc.). Therefore, the identification of new observables that are unique and "time-stable" (i.e., long persistence) will provide improved detection opportunities.

Remote methods applicable at long standoff distances and/or for possible transient airborne measurements may include optical or electro-optical methods based on the direct line of sight across a facility of interest, or large-volume air sampling based methods deployed far away from the site of interest.

Near-field methods are used at or near the site of interest and range from in-situ sensors to sensors that are deployed at close-in ranges (i.e., up to several kilometers away from the facility).

Near-field methods can measure a variety of chemical effluents including a number of chemicals that cannot readily be measured remotely plus others that may also be amenable to remote methods. Nearfield methods offer the greatest advantage for signatures that:

- are in liquid or particulate form,

- are in low concentrations,

- have low optical absorption coefficients, or 
- are heavier than air and prone to deposit on local plants and soils, and

- which are also persistent enough in the environment to deposit (and accumulate) at detectable levels.

Therefore, chemicals that are not subject to rapid degradation, have low mobility, and will not disperse readily with daily winds may be best detected using near-field detection methods. In addition, important effluents that degrade fairly rapidly in the environment and that are not suitable for remote detection should be considered for near-field detection prior to chemical degradation/transformations taking place. This may include important radioactive effluents with half-lives that are too short for practical detection using large volume air samples at remote distances.

Under some conditions near-field sensing and measurement methods can provide valuable improvements over remote measurement methods. For example, signature measurements taken by direct air sampling at long standoff distances can be highly dependent on meteorological conditions. Weather factors can dramatically limit the ability to detect a chemical (or radionuclide) on a given day if the detector system is not in the path of the process effluent's downwind flow. In these cases, the proper placement of the sensor(s) at near-field distances can significantly reduce the effects of unfavorable weather conditions and increase the probability of reliable signature detection under a broader range of weather conditions.

Alternatively, near-field methods can provide more rapid detection than remote sampling methods where detection is delayed by the time required for effluents to be transported to the remote detection equipment.

In order to establish improved detection capabilities to meet application requirements and provide technical data to answer questions about a facility's operations, ${ }^{(a)}$ it is necessary to begin with an understanding of suspected operations of specific interest and the probable effluents for these processes. In addition, the detection system requirements will depend on the behavior of these effluents in the local environment after they are released from an operating process. These considerations will provide guidance on likely observables that can be exploited to discriminate between processes of interest. In some instances, the detection of specific chemicals may eliminate candidate processes while in other cases the effluent detection may strongly implicate a limited number of processes.

\subsection{Motivation for Near-field Measurements for Detection of Nuclear Material Processing}

Many processes for the separation of $\mathrm{Pu}$ and other SNMs were developed by the U.S. and others using liquid-based chemical processing operations (e.g., bismuth phosphate separation, PlutoniumUranium Extraction [PUREX], etc.) (Stoller and Richards 1961, Cleveland 1970, Long 1978, Benedict

et al. 1981, Choppin et al. 2002). These processes were implemented at Hanford and they have served as

(a) For example: process type, products and their quantity, status and production rates, and possible enhanced processing capacity. 
the basis for processes implemented by many other nations as a number of key process flow sheets were shared internationally during the Atoms for Peace Program. ${ }^{(a, b, c)}$

Nuclear material reprocessing plants built at Hanford during the cold war were massive (see Figure 2) and processed large quantities of irradiated fuel. The Hanford plant layout and environmental control principles have been mimicked by many foreign operations, and still serve as excellent surrogates for devising near-field detection methods.

In addition to the nuclear material processing plants, reprocessing at Hanford involved the use of large underground tanks (for temporary storage of high-level waste materials) and open cribs where lowlevel waste and less hazardous materials were released directly into the soil.

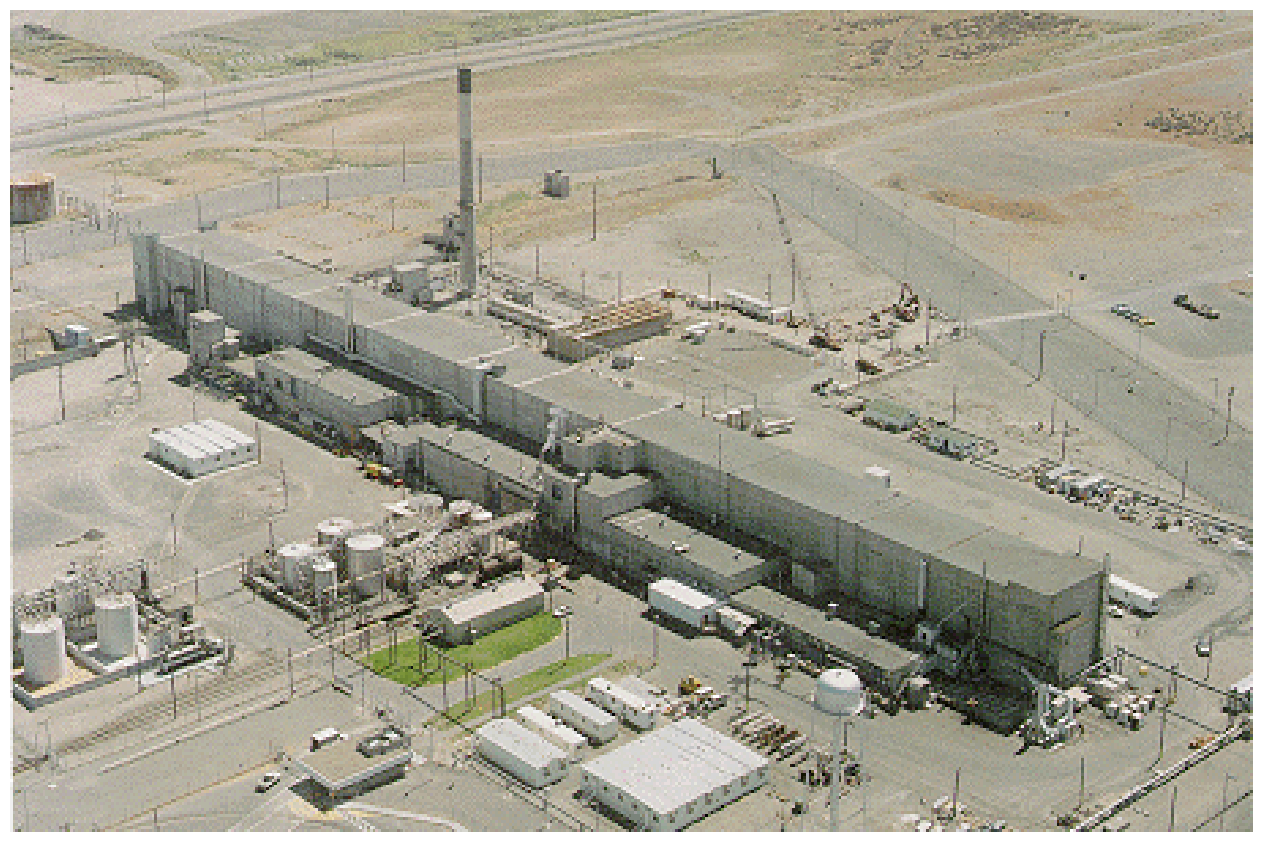

Figure 2. The PUREX Plant at Hanford. The canyon building is 60 feet tall (plus 40 feet below ground level) and 1080 feet long (http://www.fas.org/irp/imint/doe_hanford_purex_02.htm).

The operation of these processing plants and their associated support facilities typically released effluents over a variety of paths during routine, well controlled operations and occasionally from atypical operating events. The following sections will discuss:

(a) "Although details of how PUREX technology as implemented in specific plants is sometimes closely held because of proprietary and/or national security concerns, the basic reprocessing technology was declassified at the First Atoms for Peace Conference in Geneva in 1955." (Gilinsky et al. 2004, pg 43).

(b) "at the first UN Atoms for Peace Conference in Geneva (1955) the US unveiled six different studies on how to extract plutonium from spent fuel by the PUREX process---until then, a classified weapons technology." (Leventhal 2005)

(c) For example, see Flanary (1956). 
- chemicals used in nuclear fuel reprocessing with attention to:

- their volatility, as it will relate to dispersal, and

- $\quad$ their environmental stability;

- the most common emission sources from the processing facilities and from the associated supporting structures and disposal areas;

- key issues that govern effluent transport immediately after release into the environment; and

- a brief discussion of the importance of considering effluent Fate and Transport after release into the environment.

\subsection{Chemicals Used in Nuclear Fuel Processing}

The chemicals used in the nuclear fuel cycle reprocessing populate a large list. The high-volume chemicals used in these processes that may provide good probative information can be radiological, volatile, or semi-volatile. A comparison was made on more than 220 chemicals that are used in various processes throughout the nuclear fuel cycle (Probasco et al. 2002, Birnbaum et al. 2004 ${ }^{(\text {a) }}$ ). Semi-volatile chemicals are used in almost all facets of this cycle including raw material acquisition, isotope enrichment, fuel fabrication, reactor operations, actinide separations, and device manufacturing. While radiological chemicals have traditionally been used as exploitable indicators of nuclear processes, nonradiological chemicals are important because they are typically used and released in larger quantities, and can be identified and measured using a wider range of detection capabilities.

While volatile compounds may be amenable to standoff or remote detection methods, the definitive volatile species are often released at levels less than $100 \mathrm{ppb}$ and must be trapped and/or integrated to be seen with remote electro-optical sensors.

The semi-volatile chemicals (with measurable vapor pressures less than 0.1 Torr at $25^{\circ} \mathrm{C}$ ) were the focus of our work because they are more environmentally stable, and are more amenable to near-field detection methods.

The earlier analyses of chemicals used in nuclear material processing (Probasco 2002a, Birnbaum $\left.2004^{(\mathrm{a})}\right)$ provides a rich resource for understanding measurement targets.

Chemicals in the existing database (Probasco et al. 2002, Birnbaum et al. 2004 ${ }^{(\mathrm{a})}$ ) were evaluated on the basis of two criteria that are important for determining the promising options for effluent detection.

(a) Birnbaum JC, KM Probasco and DA Maughan. 2004. "Chemicals Associated with the Nuclear Fuel Cycle," PNNL-NSD-2071, Pacific Northwest National Laboratory, Richland, Washington. 
- The first criterion was the chemical's volatility (i.e., governed by vapor pressure) as the volatility directly affects the release and environmental dispersal of chemicals from a facility.

- The second criterion considered was the chemical's environmental stability. This stability refers to the chemical's ability to retain its original chemical identity (molecular form and properties) in the environment because of its chemical inertness. A highly stable compound that is largely inert to environmental processes (e.g., hydrolysis, photo-oxidation, or biochemical degradation) can exist in the environment for months and sometimes years. Conversely, chemical compounds that are highly reactive in the environment are referred to as unstable and may not survive long in the environment without undergoing some type of chemical reaction/change. These compounds, when released, typically are only measurable at or near the release point due to their short lifetime. However, if the rapid chemical conversion of definitive signature chemical effluent produces a stable and unique degradation species, the degradation products will be considered for exploitation.

221 chemicals from the nuclear processing database were analyzed on the basis of these two criteria. Of these chemicals, 86 were classified as volatiles while the remaining 135 were classified as semivolatiles. Table 1 shows the results of the volatility and stability comparison for the nuclear processing chemicals. The table indicates that the majority of both volatile and semi-volatile chemicals are reasonably stable in the environment. But many of the stable chemicals do not offer significant insights into the parent processes and, thus, they may be of little interest for practical efforts to detect and understand nuclear proliferation operations.

Finally a third criterion considers the potential importance of a chemical's detection for identifying and understanding a source process. Although this third criterion does not have an impact on the question of remote versus near-field detection, it is mentioned here for completeness.

Table 1. Summary of Stability Analysis for 221 Chemicals used in Nuclear Fuel Reprocessing based on Volatility and Environmental Stability

\begin{tabular}{|c|c|c|}
\hline \multirow{5}{*}{ 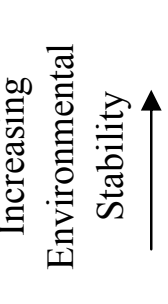 } & $\begin{array}{l}\text { Volatile } \\
\text { Chemicals }\end{array}$ & $\begin{array}{l}\text { Semi-Volatile } \\
\text { Chemicals }\end{array}$ \\
\hline & 67 & 92 \\
\hline & 13 & 12 \\
\hline & 6 & 23 \\
\hline & Total $=86$ & Total $=135$ \\
\hline
\end{tabular}

- The third criterion was a chemical's uniqueness. When a chemical is used routinely for commercial, industrial, or agricultural applications, it is designated as being a common chemical because there are likely numerous legitimate industrial sources, and relatively high concentrations may be found in the environment. An example of a common chemical is isopropyl alcohol. Its detection would offer little value and would be unlikely to provide definitive identification of the operation being used. However, if a chemical has no known commercial applications outside of the nuclear fuel cycle operations, then it would be considered to be very unique and clearly useful for detection purposes. 
Solvents to extract specific transuranics with very high separation factors would be an example. Another factor considered in determining uniqueness is the world-wide industrial production volume of a specific chemical. Chemicals that are produced in massive quantities are considered common even if many of the applications are not identified.

Figure 3 provides a summary of how the volatile and semi-volatile chemicals were distributed on a Stability - Uniqueness matrix (Probasco et al. 2005).

In Figure 3, many chemicals used for Pu and SNM reprocessing are fairly unique (or are not economically practical for more routine applications) and many are highly stable (Probasco et al. 2005). Ironically, but true in the U.S. and known foreign operations, their stability - and relatively high marginal cost to manufacture, refine, or eventually dispose of these reagents - may actually help lead to assured fugitive emissions. Because of their chemical stability against degradation by radiolysis and oxidation, they can be reused, which may increase the likelihood of both continuous and batch losses. Accidental loss of these reagents during abnormal operating conditions (i.e., cook offs) is also likely to be detected since some compounds are especially hard to incinerate or dispose of easily. From a sampling perspective, many of these stable semi-volatile compounds are environmentally robust and stickyassuring their likely deposition and accumulation in the surrounding environments. Studies at U.S. reprocessing or finishing plants that produce highly purified versions of SNMs indicate heavy recycling and chronic fugitive releases of such compounds (albeit at low but steady levels).

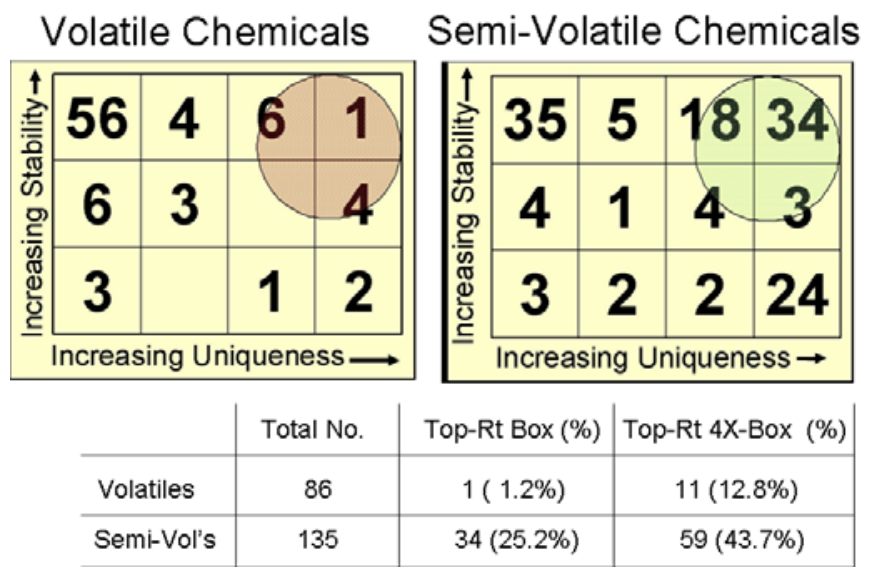

Figure 3. Summary of Results of Nuclear Processing Effluent Ranking based on Effluent Stability and Uniqueness

In addition, a number of volatile chemicals at the high uniqueness column of the chart have only moderate to low environmental stability so it may be advantageous to trap, integrate, and detect these with near-field measurements. 


\subsection{Effluent Sources from Hanford-like Nuclear Reprocessing Operations}

Effluents will likely be released concurrently from three basic routes from the processing plants:

- dissolved off-gases as stack emissions,

- vented releases from waste storage tanks, and

- advected releases from open waste disposal cribs as shown in Figure 4.

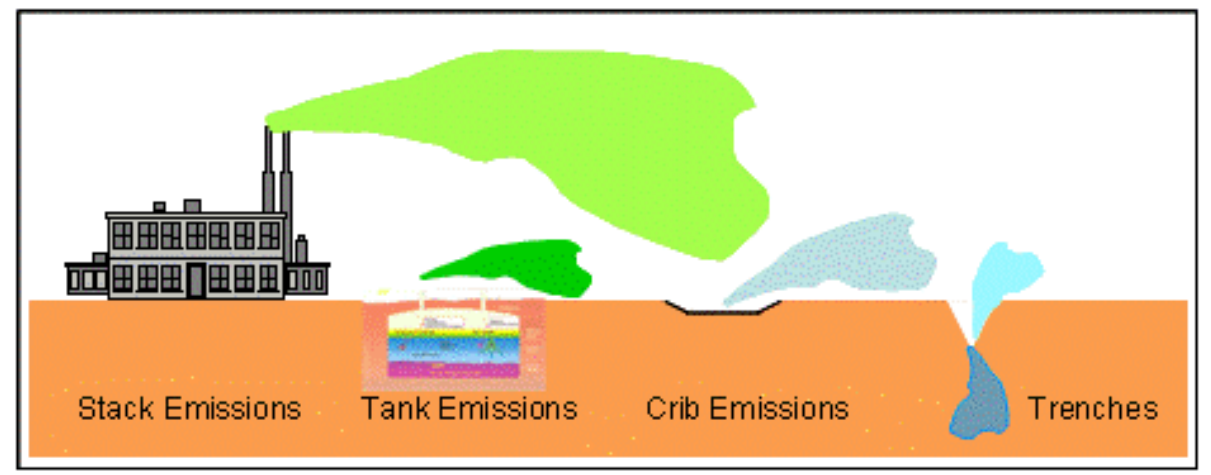

Figure 4. Hanford Nuclear Material Processing Operations Produced Effluents Directly from the Plant Stack, from Nearby Waste Storage Tanks, from In-ground Cribs (lined to limit seepage), and from open Trenches that Allowed Liquids to Seep into the Soil and Groundwater

Atmospheric conditions and the chemical properties of some effluents can result in these effluents being deposited near the release points (i.e., within several kilometers). Therefore, near-field measurements can be very important for exploiting these effluents.

\subsubsection{Direct Releases during Plant Operations}

Primary process plant releases occur from the stack and are dominated by dissolved off-gases (DOGs) from the front end of the process where dissolution of the irradiated fuel occurs. Lesser emissions from subsequent operation steps will also be present in the exhaust plume. The exhaust plume will include volatile and semi-volatile chemical species, some heavier-than-air noble gases, and particulates.

\subsubsection{Releases from Underground Waste Storage Tanks}

Underground storage tanks were used at Hanford for temporary storage of high-level liquid wastes from the spent fuel separation process operations. The process liquid waste streams included significant quantities of radioactive species that needed to be removed from the Pu product and included significant fission products (FPs) and activation products (APs), natural actinides, and man-made transuranics. In addition, the waste stream included solvents from the process stream (e.g., tributyl phosphate [TBP], etc.); degradation products of the process chemicals resulting from radiolysis, hydrolysis, or thermal effects; unwanted metal ions from the fuel cladding; processing equipment pipes and tanks; and the fuel. At 
Hanford, the tank waste materials were maintained at a high $\mathrm{pH}$ level (typically $\geq 12$ ) to minimize chemical attack on the steel tanks. Once in the tanks, the material segregated into a sludge layer, an aqueous layer, and an organic solvent layer based on density of the respective materials (Figure 5). The waste tanks had at least two vents to allow the tanks to breath and release vapors built up as a result of the radioactive energetics within the contents. Some tanks were provided with power ventilation to enhance evaporative cooling and jacketed water cooling to help control waste heat build-up while other tanks were allowed to "breath" naturally.

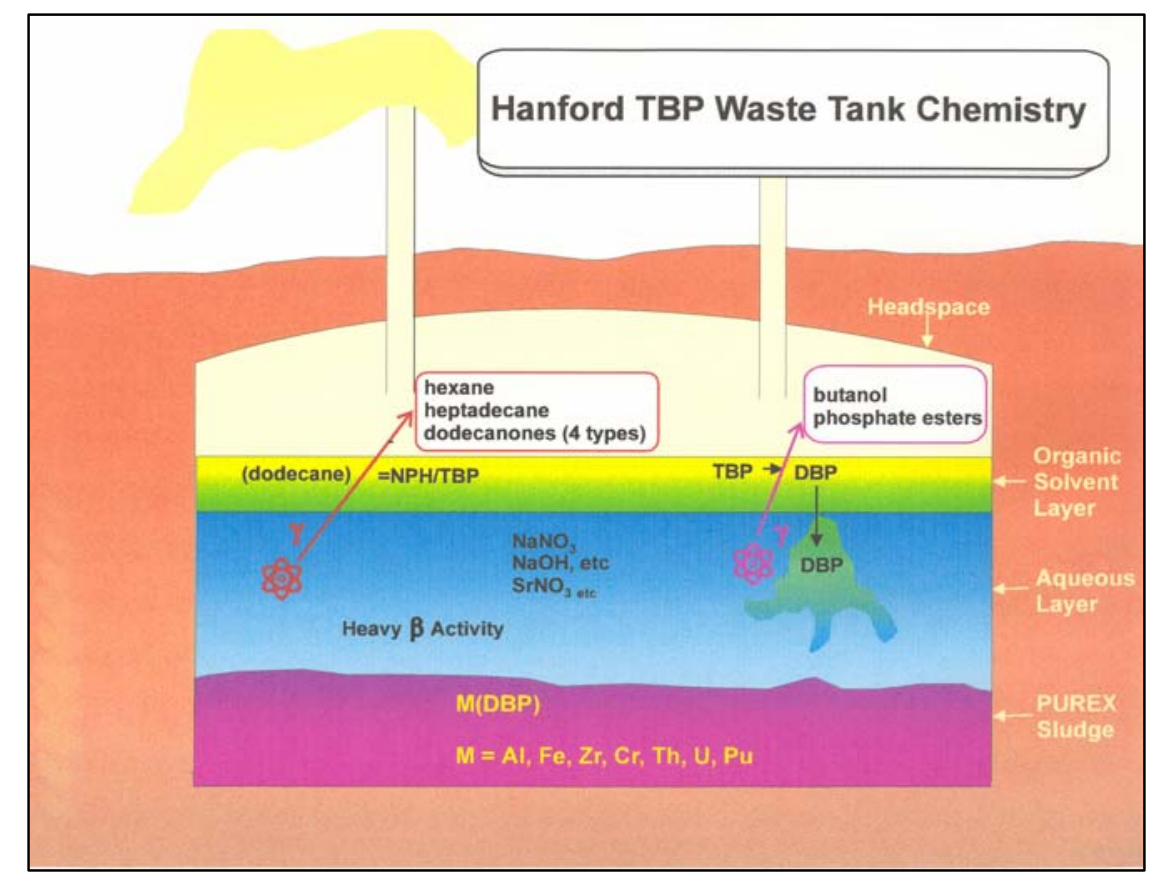

Figure 5. Illustration of Hanford Waste Tank Configuration Including Stratified Tank Contents and Important Contents and Interactions Typical for the Hanford PUREX Tanks

During long-term operation of the Hanford facilities, the materials in many of the tanks were processed in various campaigns to remove excess water, specific radionuclides, and other chemicals in order to reduce waste volumes, harvest species of interest, and manage risks.

The material in the tanks did not remain chemically static after the materials were placed in the tanks. The large quantity of radioactive species contained in the waste resulted in significant on-going radioactive decay that heated the tank contents. Thus, chemical reactions continued over time driven by both radiolysis and thermal effects. Continued breakdown of solvents and the evolution of highly branched species created additional chemical species that could be evident in local effluent releases. The appearance of "acid gases" and highly branched hydrocarbons is a tip off of radiolytic loads in the tanks. ${ }^{\text {(a) }}$

(a) James Huckaby/PNNL, private communication, 1996. 
Effluents escaping from the tanks will likely include some volatile chemicals (including lighter-thanair components), chemical species that will be heavier than air and/or sticky so they are prone to adsorb onto atmospheric particulates or nearby surfaces, and aerosols that form as heated vapors cool after leaving the tank head space.

\subsubsection{Releases from Cribs and Unintentional Outdoor Spills}

To reduce operating costs for the spent fuel reprocessing operations, it was generally desirable to reuse solvents and diluents when practical. This reduces waste streams and the cost of make-up chemicals. At Hanford, significant quantities of water were used in the PUREX process. Design operating rates for waste flow from the PUREX plant totaled more than 9.6 million gallons per day with most of the waste volume being water (Clark and Courtney 1954). More than $70 \%$ of the waste stream liquid was planned for release in the trenches. The design processing throughput for the PUREX plant was 8.33 metric tons of uranium (MTU) per day although process rates over short periods were recorded up to $30 \mathrm{MTU}$ per day (Gerber 1996). Based on these figures, rough estimates of water usage can be made for smaller operations.

Another source of waste released to open cribs involved unavoidable breakdowns of process chemistry. Even with very careful process engineering controls, U.S. practices occasionally caused temporary operation at undesirably high temperatures (i.e., "cook-offs") of reused solvents; occasionally

even with fresh mixtures. These events fundamentally changed the molecular and rheological properties of the normal working fluids and created organic-based nitrates in a mixture that was referred to as "red oils." These "red oils" have the potential to detonate at relatively low temperatures (Oregon DOE 2004, Robinson et al. 2003) in enclosed tanks, so they were often deliberately spilled to open cribs. Red oil events and other types of process "cook-offs" dictated the removal of degraded materials from the processing equipment and segregation away from the facility. Typically lined cribs were designed and constructed for this disposal.

Effluents escaping from the cribs or unintentional outdoor spills could include some volatile chemicals (including lighter-than-air components) and some chemical species that will be heavier than air and/or sticky so they are prone to adsorb onto atmospheric particulates or nearby surfaces.

\subsubsection{Summary Releases from Various Sources}

In summary, releases from each of these primary effluent sources will include some chemical and radioactive species that are lighter than air, some that are heavier than air, and some that are sticky and prone to rapidly adsorb on atmospheric particles or nearby surfaces (e.g., structure surfaces, soils, vegetation, etc.).

Some of the effluents will routinely be dispersed broadly in the atmosphere and environment by normal dispersion, lofting, and transport. Other effluents are more likely to be concentrated in the nearfield region. As will be discussed below, the near-field effects have been previously analyzed for related classes of chemicals used in chemical weapons production and use. While this application is beyond the interest of this analysis, some of the chemicals, when categorized by class, are very similar to chemicals employed in nuclear material separations and thus the implications for optimal sampling are highly relevant. 
Important effluents to be found in the near-field region include heavier-than-air effluents (e.g., heavy noble gas species, heavy molecular species, particulates, etc.) and persistent chemicals that are prone to adsorb onto particulates or material surfaces.

\subsection{Immediate Release Transport - General Observations on Atmospheric Dispersal of Stack Emissions}

Typical nuclear material reprocessing plants employ a large exhaust stack to release a significant quantity of emissions into the environment. The stack design is intended to disperse the effluents in the environment to reduce the risk to plant workers. The trajectory of the plume after release from a stack into the atmosphere will be governed by local obstructions (i.e., the large plant building, etc.), the stack design (including height) and its location, plume properties, and meteorological conditions at the time of release (Briggs 1969, Yeh and Huang 1975). For example,

- Atmospheric turbulence may cause the plume to rapidly mix and disperse in the atmosphere while under other conditions the plume may remain distinct and relatively compact for some time after release.

- Plume buoyancy (plume temperature and atmospheric temperature profiles) may cause the visible exhaust plume to rise into the atmosphere after release while under other conditions that visible plume will only rise to an intermediate level as determined by atmospheric temperature profiles, etc. Under some atmospheric conditions that visible plume will actually leave the stack and be driven back to the ground surface near the point of release (see plume in Figure 6).

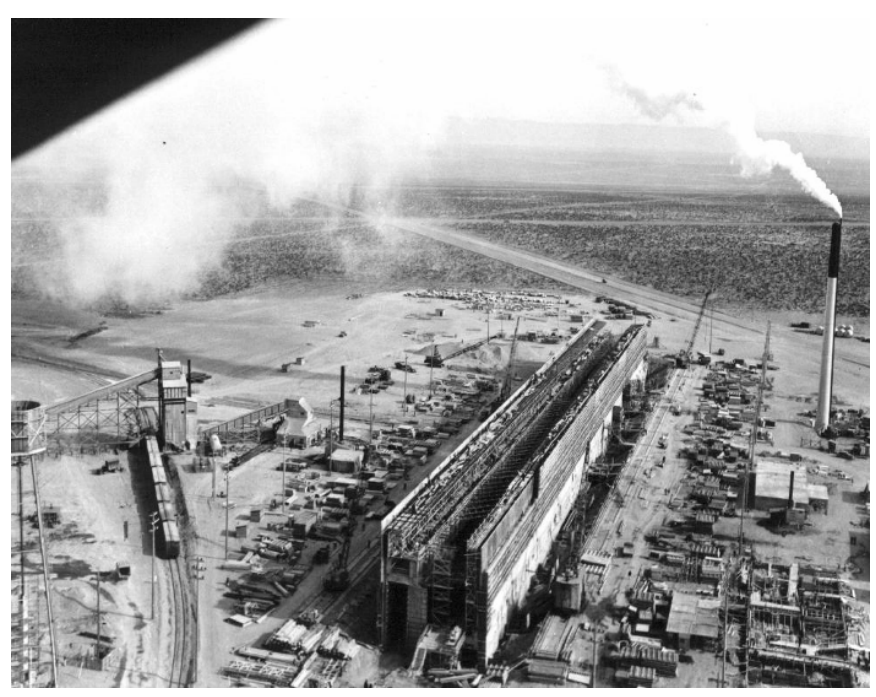

Figure 6. The Hanford T-plant is seen during Construction. The plume release from the plant stack shows deliberate fog-oil emissions flow pattern testing. Many conditions can result in plumes striking the ground; in this case, a southeasterly wind drives the fog-oil to the left side of the photograph. 
Under ideal administrative controls, reprocessing would only be performed under suitable "windrose" and atmospheric stability conditions in order to provide optimal plume dispersal and to minimize undesirable effects near the production facility. In U.S. historical practice, these administrative controls were frequently by-passed in order to achieve production goals. In addition, these processing plants are very large, continuous operations that cannot be quickly "turned on" and "turned off" in response to changing atmospheric conditions. It is likely that foreign plume releases will also occur under a variety of less-than-optimal conditions in order to achieve production goals. Whether and how one would exploit released materials could be based on the ability to observe $\mathrm{NH}_{3}$ and $\mathrm{NO}_{\mathrm{x}}$ plumes present during reprocessing operations.

However, not all potential process signature species in the plume are likely to follow the path of the visible plume. Some plume species are inherently heavier than air (e.g., heavy noble gases, etc.), and/or are sticky and very prone to agglomerate or to adsorb on co-process or atmospheric particulates, which results in heavier-than-air properties. Based on atmospheric turbulence conditions, heavier-than-air components are likely to fall from the visible plume and deposit on nearby surface features.

Key insights on probable plume releases reaching the ground near process stacks can be gained from previous analyses of releases from process stacks associated with the production of chemical weapons materials (Sanches et al. 1991, 1993a, 1993b). This work was conducted in support of CW treaty monitoring efforts with the objective of determining distances from the process stacks where key process signatures could most likely be detected at ground level after a suitable delay ( $\sim 10$ days) to carry out a challenge inspection. Although the chemical weapons question is beyond the scope of this investigation, the results of these studies are very relevant to understanding the behavior of plumes released by the nuclear material reprocessing plant operations. Key aspects of the earlier modeling and the findings will be described below as they provide valuable insights relative to the near-field monitoring opportunities for detecting nuclear proliferation operations.

\section{$\underline{\text { Key Points from Sanches Study }}$}

The Sanches study's (Sanches et al. 1991) objective was "to determine ground locations down-wind from a chemical weapons production plant exhaust stack with the highest potential constituent concentrations in the plume" (i.e., airborne effluent constituent concentrations as seen by an air sampling sensor at ground level). This was achieved by analytically modeling the exhaust plume trajectory in the atmosphere after release from a process stack and then extending the analysis to predict relative plume concentrations at ground level. Although the chemical constituents of exhaust plumes from $\mathrm{CW}$ production and from nuclear reprocessing will differ significantly, the general behavior of the exhaust plumes in the atmosphere will be similar for comparable physical properties of the plant stack, the plume, the surrounding atmosphere, and of course, the class of chemical compounds. Many of the organophosphates used to manufacture chemical weapons closely mimic some of the important compounds found in nuclear reprocessing operations. 
The analyses were conducted using the Industrial Source Complex Short Term (ISCST) model ${ }^{(a)}$ (TRC 1987) and considered only controlled stack emissions. (Fugitive emissions from other plant sources were not considered as they are likely to be highly plant- and site-specific. For comparison to the Hanford situation, potential emissions from other sources including the underground waste tanks, trenches, and cribs were not considered.) The analyses considered a variety of atmospheric conditions, stack heights, and stack effluent release conditions and evaluated the sensitivity of the predicted plume trajectories to changes in the individual variables. Specifically, the sensitivity analyses considered:

- Various atmospheric stability classes (Pasquille-Gifford classes) ranging from stable to extremely unstable,

- Horizontal wind speed $(1.5-9 \mathrm{~m} / \mathrm{s})$,

- Atmospheric mixing height ${ }^{(b)}(100->250 \mathrm{~m})$,

- Stack height (15-45 m),

- Effluent temperature leaving the stack $\left(20-300^{\circ} \mathrm{C}\right)$, and

- Effluent velocity leaving the stack $(4.5-20 \mathrm{~m} / \mathrm{s})$.

The analyses showed that the atmospheric stability conditions had significant effects on the predicted plume trajectory. In order to more clearly understand the effects of the remaining variables on the plume trajectories, the subsequent sensitivity analyses were conducted for neutral and stable atmospheric conditions. (Typically this is representative of nighttime conditions in the absence of solar heating and, typically, has lower winds, greater atmospheric stability, and lower turbulence.) Although this may seem like an artificial simplification, for plants that operate full time, a significant portion of each day is likely under these more stable atmospheric conditions.

The analyses determined that stack height also had a significant impact on the plume trajectory as shown in Figure 7, which shows the relative air concentration of emissions at ground level for two stack heights under stable and neutral atmospheric conditions. Key insights provided from this plot include:

- Very low concentrations of stack effluents are found at ground level immediately adjacent to the stack,

- Predicted ground level concentrations increase as distance increases from the stack up to a certain point, after which the concentrations diminish (although the concentrations may remain significant to distances 3-5 times the distance of the peak concentration), and

- The distance corresponding to the peak ground level concentrations is inversely related to the stack height (for the example shown, a 15-m stack results in a maximum concentration distance of $\sim 0.5 \mathrm{~km}$ while a $46-\mathrm{m}$ stack results in a maximum concentration distance of $\sim 2 \mathrm{~km}$ ).

(a) The ISCST model can account for settling of large particulates but does not include different settling rates for chemical constituents of different weights or of chemical adsorption on plume or atmospheric particulates. (Sanches et al. 1991, page H-1)

(b) "The vertical distance through a ground-adjacent unstable or neutral layer to the bottom of the first stable layer." (Sanches et al. 1991, page 74) 


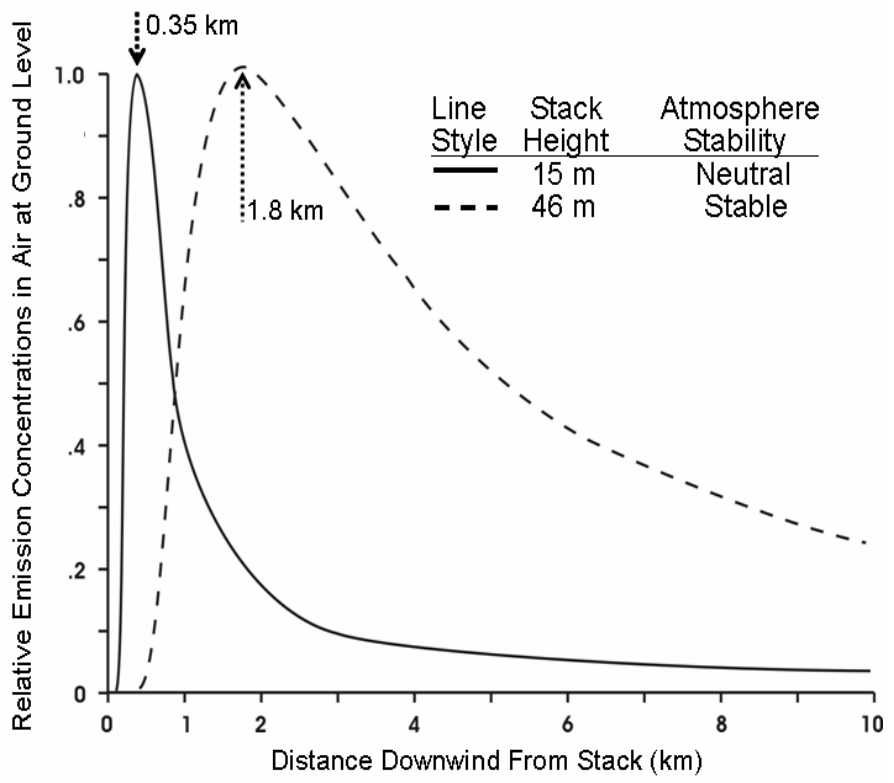

Figure 7. Normalized Predicted Air Concentration at Ground Level for Heavy, Semi-Volatile Effluents Released During Atmospheric Conditions Suitable for Effective Effluent Dispersion from Plume Trajectory Modeling by Sanches et al. (1991). Curves show effect of several stack heights (15-m and 46-m). (Sanches et al. 1991, footnote 6, Figure 22, page 78).

It is important to keep in mind that this figure presents the relative concentrations (i.e., each curve is normalized so its peak amplitude is unity). Thus, no absolute concentration implications can be drawn from these curves but the spatial distribution insights are relevant.

Sensitivity analyses for each of the remaining individual variables (e.g., horizontal wind speed, mixing height, stack temperature, and stack velocity) exhibited peak concentration distance changes of less than 20\%. Thus, the results illustrated in Figure 7 represent the key results.

It should also be noted that although the atmospheric dispersion models have improved since then, it is believed that the key features of the earlier results remain valid.

a) The trends illustrated in this plot provide strong implications for the near-field detection of chemical effluents released from nuclear processing facility stacks during desired atmospheric operating conditions. (The peak airborne concentrations of heavier-than-air and sticky chemical constituents released under neutral or stable atmospheric conditions are likely to be near the ground in the predicted range from the stack.)

b) Heavy stack emission effluents are unlikely to be found in the air at ground level immediately adjacent to the facility.

c) For high stacks (i.e., 30-45 meters), ground level emissions are likely to peak at distances of 1-2 $\mathrm{km}$ away from the stack. 
d) Significant ground level effluent concentrations in the air will likely occur at significant distances beyond the peak concentration range.

If process and site-specific insights are required, detailed effluent transport modeling can be performed to assess effluent dispersal under specific site and weather conditions. These models can take into account local topography (e.g., valleys, ridges and mountains, rivers and lakes, etc.), local weather conditions (either general trends or actual climate conditions), and facility configurations. These analyses can provide valuable insights if a facility of interest is located in a region with significant local topographical barriers or unique weather patterns that strongly affect the dispersal of effluents released from the facility (e.g., channeling of winds through valleys and around high ridge lines, etc.).

\subsection{Process Signature Fate and Transport after Release to the Environment}

Another key consideration, when evaluating sensing and measurement technologies for the detection of a nuclear reprocessing plant operation, is the Fate and Transport (F\&T) of specific nuclear process signatures. The F\&T effects are important to consider because different effluents can behave very differently in the environment following release from the reprocessing plant. Some effluents may tend to rapidly disperse in the environment, others may undergo rapid destruction or conversion to other chemical forms, while others may tend to deposit near the point of release and remain stable for long periods of time. Chemicals that remain in the environment near the point of release tend to concentrate in different segments of the environment. Some may tend to deposit in the soil, some in local vegetation, some in the surface and subsurface water, etc. Thus, understanding the basic fate and transport tendencies/effects for key effluents can provide important guidance regarding the probable survival and location of a given chemical (or family of chemicals) in the environment. There is no point in looking for chemicals that are rapidly transformed after release (e.g., lost to rapid hydrolysis, photolysis, microbial breakdown, etc.) using slow methods or sensors removed from the point of release, and it may be fruitless to look for chemicals in low probability regions of the environment long after their release.

A variety of F\&T modeling tools have been developed for specific temporal and spatial application domains. These range from:

- Models that can predict the short-term fate and dispersal of effluents released from a specific event (e.g., a chemical spill, etc.) to

This class of F\&T models could be important for proliferation detection if a reprocessing plant is only being run for episodic, batch mode operations. In addition, these short-term models may be important for process signatures that are relatively short lived.

A number of these models have been developed and evaluated to allow effective emergency response to transportation and industrial accidents and more recently, to potential terrorist events. Discussions of models for emergency situation analysis include Mazzola and Addis (1995) and NWSI (2004).

- Models that consider the effects of long-term chemical releases over large areas where the releases are fairly uniform (e.g., herbicide or pesticide applications over large farming regions [for example, California's central valley], etc.). 
This class of F\&T models could be important for long-running nuclear reprocessing operations and long-lived, low-mobility process signatures that tend to be captured in the environment near the reprocessing operation (e.g., long-lived semi-volatile chemicals that tend to adsorbed on soils and surfaces near the reprocessing plant or captured in flora or fauna near the plant, etc.).

These methods are applicable to a broad range of problems and a number of tools have been developed to support analysis of suitable situations (MacKay 1979, 1991, 2001; MacKay and Paterson 1981, 1982; MacKay et al. 2001; McKone 1993a, 1993b, 1993c; McKone and Lawton 1986; Whelan et al. 1992; Webster et al. 1998, 2003). These methods assume that lateral motion of chemicals into and out of the computational cell are balanced (i.e., incoming drift is balanced by exiting drift). An example of a tool developed for this type of analysis is CalTOX (CalTOX 1993), which was developed for the California Environmental Protection Agency to evaluate chemical F\&T and accumulation in the environment to support the evaluation of health risks to workers and local residents. A number of other research groups have also developed useful tools for analysis of this type.

- Models that predict the migration of chemicals or other stable species well beyond the area of their application (e.g., pesticides migrating from agricultural areas to arctic regions, etc.) to

This class of F\&T models could be important mobile, long-lived process signatures that can migrate long distances with atmospheric weather patterns (e.g., long-lived radionuclides migrating across international borders, etc.).

One key motivator for the development of these models has been the unanticipated discovery of semi-volatile compounds much farther from chemical sources than anticipated. For example pesticides have been detected in the arctic far from any areas where they are applied (Rice 1997). Additional studies have documented the presence of organic chemicals far beyond the range of their use and application (Barrie and Schemenuaer 1986; Bennett et al. 1998; Matthies et al. 1999; Matthies and Scheringer 2001; Unsworth et al. 1999; Scheringer et al. 2001). These results stimulated the development of additional methods based on concerns about: (a) pollution and hazardous material build up in the environment from distant sources; (b) global atmospheric transport effects; and (c) global warming concerns. Significant research has been conducted to understand these effects and a number of tools have been developed to help predict and evaluate the effects for practical applications (Beyer 1999; Beyer and Matthies 2000, 2001a, 2001b, 2002; Beyer et al. 2000, 2001). A number of these investigations gave special attention to organic and semi-volatile chemicals.

As noted above, field measurements have found that a number of organic and semi-volatile chemicals have been found far beyond their range of application and use. The conventional understanding of chemical transport at the time of these discoveries did not provide a suitable explanation for this unexpected chemical transport. One example of an unexpected transport mechanism is noted below. 
In the mid-1980s experimental evidence emerged indicating that some pollutants, including pesticides, were being found in fog droplets at unexpected concentration levels (Barrie and Schemenuaer 1986; Glotfelty et al. 1987; Turner et al. 1989; Schomburg et al. 1991; Seiber et al. 1993). Subsequent investigations indicated that chemical pickup and transport by fog droplets could be contributing in an unanticipated way to dispersal of some chemicals beyond the range expected in the absence of the fog transport (Glotfelty et al. 1990; Goss 1993, 1994; Valsaraj et al. 1993; Anastacio 2001).

Some semi-volatiles, because of their high surface tension and associated hydrophobic nature, can readily concentrate and be lofted from ponds and soils as surface contaminants on small hydrosols $(<10 \mu \mathrm{m}$ diameter $)$. This counter intuitive mechanism of migration of low-volatility compounds on fogs is in fact effective and the root explanation for effective lofting of organo phosphorus (OP) compounds and other pesticides (organo-chlorines such as DDT) (Glotfelty et al. 1987; Bidleman 1988; Anastasio and McGregor 2001; McGregor and Anastasio 2001).

Initial discussions of these points (Kelly ${ }^{(\mathrm{a}, \mathrm{b})}$ ) under the CALIOPE program led to increased awareness of aerosol and hydrosol monitoring. The point to reiterate is that aeration of cribs/tank vents can occur by movements of early morning mists or evening fogs (Glotfelty et al. 1987). These are more in evidence during the atmospheric conditions suitable for stable plume lofting; e.g., those times most suitable for starting a reprocessing campaign to effectively disperse the volatile fission products.

A number of agencies and research groups, including DOE (Mazzola and Addis 1995), have evaluated the merits of the alternative analysis tools. For example, the U.S. Environmental Protection Agency has several websites that provide background information on F\&T models (see information at http://www.epa.gov/epahome/models.htm and http://www.epa.gov/Region8/r8risk/models.html ).

\subsection{Validation of Long-term Semi-volatile Residuals at Hanford}

Preliminary experiments were conducted under a complementary DOE NA-22 project to assess chemical signatures in the Hanford environment associated with the PUREX plant operation and its waste and by-products which are stored in underground tanks (PUREX and the tanks were discussed above). Hanford's 200 East Area (see map, Figure 8) contains both the PUREX plant and a number of underground waste storage tanks. The PUREX plant began operation in 1955 and was operated until 1972. It was operated for a short time in 1982-1983 before being formally closed in 1990 and then deactivated in 1993. The Hanford waste tanks have been used to store Hanford reprocessing operation wastes, including PUREX wastes, from the early Hanford operations in the mid-1940s to the present.

(a) Kelly JF. 1996. "Historical Releases at Hanford," presented to CALIOPE Signatures Review at Lawrence Livermore National Laboratory, Livermore, California, January 26-27, 1996.

(b) Kelly JF. 1999. "Fate and Transport Issues in Effluent Releases," presented to 6th Interim Technical Review of CALIOPE, at Sandia National Laboratory, Livermore, California. 


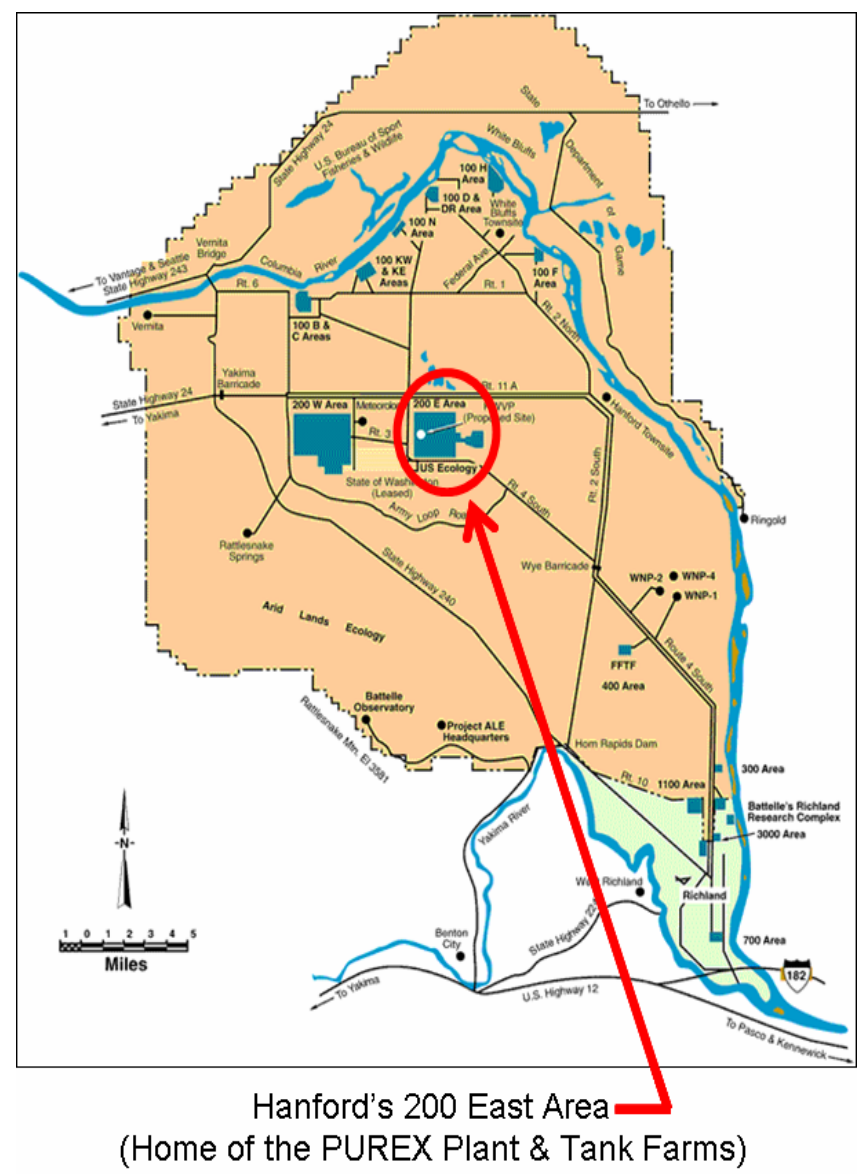

Figure 8. Map of the Hanford Site Identifying the 200 East Area Which Includes the Hanford PUREX Plant and a Number of Underground Waste Storage Tanks Used to Store Radioactive Waste Resulting from Past Hanford Nuclear Reprocessing Operations

The PUREX operation employed process chemicals within the group discussed earlier in Section 2.1. Tributyl-phosphate (TBP) dissolved in NPHs (normal paraffinic hydrocarbons) was used in large quantities in the PUREX separation process. TBP and most of the components of the NPH solvent (i.e., dodecane) are stable, semi-volatile chemicals that are sticky and prone to adsorb onto exposed surfaces and particulates (including soils). Soil samples were collected in 2004 near the inactive PUREX plant and analyzed to determine if TBP and diluent chemicals (NPHs) or their degradation products were present in the soils in any significant levels. Since the active use of TBP/NPHs in high volumes at Hanford ended several decades ago, detection at this time seemed likely to be due to old releases from the PUREX operations or more recent emissions venting from old process wastes stored in the underground tanks.

The soil samples were analyzed and found to contain high quantities of NPH species and very high quantities of their expected degradation products (e.g., alcohols, aldehydes, carboxylic acids, and multiple branched hydrocarbons) (Birnbaum et al. 2004). The findings were consistent with more than one contaminating source; i.e., a mixture of NPH components with aldehydes and other oxidized species support very old depositions, PUREX, with more recent deposition, waste storage tanks.) TBP was not 
detected in the soil samples although it is expected that all or most of the TBP would be degraded including the TBP present in the waste storage tanks. To date, the samples have not been analyzed for DBP or other TBP degradation products.

These results corroborate the long-term value of unique, highly stable semi-volatile chemicals deposited on soils near a candidate reprocessing plant for assessment of either on-going or past plant operations. Likely sources of these persistent chemical residues include earlier PUREX plant operations (ended in the mid-1980s) and/or from the limited emissions of these chemicals from the vented underground waste storage tanks that contain wastes from the earlier operation of the PUREX plant and other Hanford processing operations.

\subsection{Summary}

This analysis has focused on the opportunity to exploit important, persistent process chemical effluent signatures from nuclear material processing plants and their associated supporting facilities to provide more effective nuclear non-proliferation monitoring.

The U.S. PUREX process and operations served as the basis for this discussion as the PUREX process was disclosed during the Atoms for Peace era, and it has been adopted by many nations in the subsequent years. Thus, Hanford's PUREX operations serve as a useful surrogate for evaluating these processes. This report described:

- Key chemical groups employed in the PUREX and nuclear materials reprocessing operations that offer significant process insights and exhibit good persistence in the environment;

- Effluent release sources from the Hanford PUREX operation and its associated support facilities;

- Plume propagation after the effluent plumes are released from process stacks and the probability that under some common atmospheric conditions, the plume likely reaches the ground within several kilometers of the stack;

- The importance of considering the fate of chemicals in the environment to ensure that detection methods target viable signatures and in likely locations in the environment; and

- Results of a preliminary analysis of soil samples collected near the Hanford PUREX plant and its associated supporting facilities that confirmed the presence of persistent chemical residues indicative of the PUREX plant processes.

In summary, the near-field domain around potential nuclear material reprocessing operations offers a valuable opportunity to detect chemical signatures that can be very important for understanding facility operations, including probable processes being employed. 


\subsection{References}

Anastasio C and KG McGregor. 2001. "Chemistry of fog waters in California's Central Valley: 1. In situ photoformation of hydroxyl radical and singlet molecular oxygen," Atmospheric Environment, 35:1079-1089.

Barrie LA and RS Schemenuaer. 1986. "Pollutant Wet Deposition Mechanisms in Precipitation and Fog Water," Water, Air and Soil Pollution, 30:91-104.

Benedict M, TH Pigford and HW Levi. 1981. Nuclear Chemical Engineering, McGraw Hill Book Company. (See Chapter 10 - Fuel Reprocessing, pages 457 through 564)

Bennett DH, TE McKone, M Matthies and WE Kastenberg. 1998. "General formulation of characteristic travel distance for semi-volatile organic chemicals in a multi-media environment," Environmental Science \& Technology 32:4023-4030.

Beyer A. 1999. Assessment of Long-range Transport of Persistent Organic Pollutants, Ph.D. Thesis (Department of Mathematics and Computer Science), University of Osnabruck, Germany.

Beyer A. and M Matthies. 2000. "Atmospheric long-range transport and persistence of multiphase partitioned, organic compounds." Conference proceedings of the 4th Italian-German Workshop on Tropospheric Chemistry, in Marienthal.

Beyer A and M Matthies. 2001a. "Long-Range Transport Potential of Semivolatile Organic Chemicals in Coupled Air-Water Systems," Environmental Science and Pollution Research 8:173-179.

Beyer A and M Matthies. 2001b. Criteria for Atmospheric Transport Potential and Persistence of Pesticides and Industrial Chemicals. Final Report, German Federal Environmental Agency, Berlin, Germany, 2001.

Beyer A and M Matthies. 2002. "ELPOS - Criteria for Persistence and Long-range Transport Potential of Pesticides and Industrial Chemicals," available on the internet at http://www.usf.uos.de/projects/elpos/

Beyer A, D Mackay, M Matthies, F Wania and E Webster. 2000. “Assessing Long-Range Transport Potential of Persistent Organic Pollutants,” Environmental Science \& Technology 34:699-703.

Beyer A, M Scheringer, C Schulze and M Matthies. 2001. "Comparing Representations of the Environmental Spatial Scale of Organic Chemicals," Environmental Toxicology and Chemistry, 20:922-27.

Bidleman TF. 1988. "Atmospheric Processes - Wet and dry deposition of organic compounds are controlled by their vapor particle partitioning," Environmental Science \& Technology 22(4):361-367.

Birnbaum JC, KM Probasco and DA Maughan. 2004. Measuring and Characterizing Potential Signature Compounds. PNNL-14977, Pacific Northwest National Laboratory, Richland, Washington. 
Briggs GA. 1969. Plume Rise (AEC Critical Review Series). Nuclear Safety Information Center, U.S. Atomic Energy Commission, Division of Technical Information.

CalTOX. 1993. "CalTOX, a Multimedia Total-Exposure Model for Hazardous-Waste Sites, Part II: The Dynamic Multimedia Transport and Transformation Model," December 1993. Further information available at: http://www.dtsc.ca.gov/AssessingRisk/upload/techman2.pdf

Choppin GR, JO Liljenzin and J Rydberg. 2002. Radiochemistry and Nuclear Chemistry, 3rd Ed., Butterworth-Heinemann, Woburn, Maine. (See Chapter 21, "Nuclear Fuel Cycle," pp. 583-641.)

Clark BE Jr. and JJ Courtney. 1954. An Introduction to the PUREX Plant, General Electric Hanford, HW-32413, p 71.

Cleveland JM. 1970. The Chemistry of Plutonium, Gordon and Breach Science Publishers, New York. (See Part IV on Chemical Processing which comprises Chapters 18 through 20, pages 461-584. This includes separation from Irradiated Reactor Fuel, Conversion Process, Recovery, and Waste Disposal.)

Flanary JR. 1956. "Solvent Extraction Separation of Uranium and Plutonium from Fission Products by Means of Tributyl Phosphate," Volume 9, Reactor Technology and Chemical Processing in Proceedings of the International Conference on the Peaceful Uses of Atomic Energy, United Nations, New York, pp. 528-531.

Gerber MS. 1996. The Plutonium Production Story at the Hanford Site: Processes and Facility History, WHC-MR-0521-Rev. 0, Westinghouse Hanford Co., p 4-14.

Gilinsky V, M Miller and H Hubbard. 2004. A Fresh Examination of the Proliferation Dangers of Light Water Reactors, The Nonproliferation Policy Education Center, Washington, D.C., p 43.

Glotfelty DE, JN Seiber and LA Liljedahl. 1987. “Pesticides in Fog,” Nature 325:602-605.

Glotfelty, DE, MS Majewski and JN Seiber. 1990. "Distribution of Several Organophosphorous Insecticides and Their Oxygen Analogues in a Foggy Atmosphere," Environmental Science \& Technology 24(3):353-357.

Goss KU. 1993. "Adsorption of Organic Vapors on Polar Mineral Surfaces and on a Bulk Water Surface: Development of an Empirical Predictive Model," Environmental Science \& Technology 28:640-645.

Goss KU. 1994. "Predicting the enrichment of organic compounds in fog caused by adsorption on the water surface," Atmospheric Environment 28(21):3513-3517.

Leventhal P. 2005. Everything You Always Wanted to Know About the NPT But Were Afraid to Ask, A Selection of Annotated Documents Bearing on Issues Before the 2005 NPT Review Conference, Nuclear Control Institute, Washington, D.C. 
Long JT. 1978. Engineering for Nuclear Fuel Reprocessing, published for the Office of Technical Information, U.S. Department of Energy by the American Nuclear Society, La Grange Park, Illinois.

MacKay D. 1979. "Finding fugacity feasible,” Environmental Science and Technology 13:1218-1223.

MacKay D and S Paterson. 1981. "Calculating fugacity," Environmental Science and Technology 15:1006-1014.

MacKay D and S Paterson. 1982. "Fugacity revisited," Environmental Science and Technology 16:654-60.

MacKay D. 1991. Multimedia Environmental Models: The Fugacity Approach, Lewis Publishers, Chelsea, Michigan.

MacKay D, E Webster, I Cousins, T Cahill, K Foster and T Gouin. 2001. An Introduction to Multimedia Models - Final Report. Prepared as a background paper for OECD Workshop Ottawa, October 2001 by Canadian Environmental Modeling Centre. Report No 200102.

MacKay D. 2001. Multimedia Environmental Models: The Fugacity Approach, Second Edition by Lewis Publishers, Inc., Boca Raton, Florida. ISBN: 1566705428.

Matthies M, A Beyer and D Mackay. 1999. "Long-Range Transport Potential of PCB and PCDD/F and their Classification," Conference Proceedings DIOXINE 1999, Organohalogen Compounds 41:347-351.

Matthies M and M Scheringer. 2001. "Long-Range Transport in the Environment - Editorial for Special Issue of ESPR,” Environmental Science and Pollution Research 8:149.

Mazzola CA and RP Addis. 1995. Atmospheric Dispersion Modeling Resources, 2nd Edition, U.S. DOE, Emergency Management Advisory Committee, Subcommittee on Consequence Assessment and Protective Actions. (Available on the internet at http://www.etsimo.uniovi.es/gma/admr.pdf)

McGregor KG and C Anastasio. 2001. "Chemistry of fog waters in California's Central Valley: 2. Photochemical transformations of ammino acids and alkyl amines," Atmospheric Environment 35:1091-1104.

McKone TE and DW Lawton. 1986. "Screening the potential risk of toxic substances using a multimedia compartment model: Estimation of human exposure," Regul. Toxicol. Pharmacol 6:359-380.

McKone TE. 1993a. CalTOX, A multimedia total-exposure model for hazardous waste sites Part I: Executive Summary. UCRL-CR-111456PtI. Lawrence Livermore National Laboratory, Livermore, California.

McKone TE. 1993b. CalTOX, A multimedia total-exposure model for hazardous waste sites Part II: The dynamic multimedia transport and transformation model. UCRL-CR-111456PtII. Lawrence Livermore National Laboratory, Livermore, California. 
McKone TE. 1993c. CalTOX, A multimedia total-exposure model for hazardous waste sites Part III: The multi-pathway exposure model. UCRL-CR-111456PtIII. Lawrence Livermore National Laboratory, Livermore, California.

NWSI. 2004. Non-weather Related Emergency Product Specification, National Weather Service Instruction 10-518, Sept. 8, 2004. (http://www.nws.noaa.gov/directives/sym/pd01005018curr.pdf)

Oregon DOE. 2004. Hanford Cleanup: The First 15 Years, Oregon Department of Energy, page 15, October 2004 (http://www.oregon.gov/ENERGY/NUCSAF/docs/15year.pdf)

Probasco KM, JC Birnbaum and AD Maughan. 2002. Potential Signatures of Semi-volatile Compounds Associated with Nuclear Processing. PNNL-13922, Pacific Northwest National Laboratory, Richland, Washington.

Probasco KM, JC Birnbaum, AD Maughan, JF Kelly and JS Hartman. 2005. Exploiting Semi-volatile Chemical Signatures to Understand Nuclear Processing Operations. PNNL-15098, Pacific Northwest National Laboratory, Richland, Washington.

Rice CP and SM Chernyak. 1997. "Marine Arctic Fog: An Accumulator of Currently Used Pesticides," Chemosphere 35:867-878.

Robinson RN, DM Gutowski and W Yeniskavich. 2003. Control of Red Oil Explosions in Defense Nuclear Facilities, A Defense Nuclear Facilities Safety Board Technical Report, DNFSB/TECH-33, November 2003 (on-line at http://www.dnfsb.gov/pub docs/dnfsb/tr_20031113.pdf)

Sanches ML, CL Randolph, JD Barden, S Bradley and LL Laughlin. 1991. Chemical Weapons Convention (CWC) Signatures Analysis. Systems Planning Corporation, prepared for Defense Nuclear Agency under contract DNA001-C-0168.

Sanches ML, CR Russell and CL Randolph. 1993a. Chemical Weapons Convention (CWC) Signatures Analysis: Technical Analysis, by Defense Nuclear Agency, B171-788.

Sanches ML, C Dimaggio, WC Golbitz, R Gallagher, DW Squire, J Barden, S Bradley, CL Bothe, MM Crenshaw, LA Hernon-Kenny and MR Kuhlman. 1993b. Analysis of Signatures and SES Associated with CWC Noncompliance Scenarios. Technical Report No. 1449, Defense Nuclear Agency.

Scheringer M, K Hungerbühler and M Matthies. 2001. "The Spatial Scale of Organic Chemicals in Multimedia Fate Modeling: Recent Developments and Significance for Chemical Assessments (Review Article)," Environmental Science and Pollution Research 8:150-155.

Schomburg CJ, DE Glotfelty and JN Selber. 1991. "Pesticide Occurance and Distribution in Fog Collected near Monterey, California," Environmental Science \& Technology 25(1):155-160.

Seiber JN, BW Wilson and MM McChesney. 1993. "Air and fog deposition residues of four organophosphate insecticides used on dormant orchards in the San Joaquin Valley, California," Environmental Science \& Technology 27(10):2236-2243. 
Stoller SM and RB Richards. 1961. Reactor Handbook, Vol. II, Fuel Reprocessing, Interscience Publishers, Inc., New York.

TRC. 1987. Industrial Source Complex (ISC) Dispersion Model User's Guide, Second Edition (Revised), Vol. 1, TRC Environmental Consultants, Inc. Prepared for the U.S. Environmental Protection Agency. NTIS, PB88-171475.

Turner B, S Powell, N Miller and J Melvin. 1989. A Field Study of Fog and Dry Deposition as Sources of Inadvertent Pesticide Residues on Row Crops. Report EH 89-11, California Department of Food and Agriculture.

Unsworth JB, RD Wauchope, AW Klein, E Dorn, B Zeeh, SM Yeh, M Akerblom, KD Racke and B Rubin. 1999. "Significance of the Long Range Transport of Pesticides in the Atmosphere," Pure Appl. Chem. 71(7):1359-1383.

Valsaraj KT, GJ Thoma, DD Reible and LJ Thibodeaux. 1993. "On the enrichment of hydrophobic organic compounds in fog droplets," Atmospheric Environment 27A:203-210.

Webster E, D Mackay and F Wania. 1998. "Evaluating Environmental Persistence,” Environmental Toxicology and Chemistry 17:2148-2158.

Webster E, J Hubbarde, D Mackay, L Swanston and A Hodge. 2003. Development of Tools to Improve Exposure Estimation for Use in Ecological Risk Assessment: The TaPL3 Upgrade. Report to Environment Canada. CEMC Report, Trent University, Peterborough, Ontario.

Whelan G, JW Buck, DL Strenge, JG Droppo, Jr. and BL Hoopes. 1992. “Overview of Multimedia Environmental Pollutant Assessment System (MEPAS)," Hazardous Waste \& Hazardous Materials 9(2):191-208.

Yeh G-T and C-H Huang. 1975. "Three-Dimensional Air Pollutant Modeling in the Lower Atmosphere," Boundary-Layer Meteorology 9:381-390. 